\title{
Grading and sorting as a method of market segmentation for agricultural products
}

\author{
M. T. G. Meulenberg \\ Department of Marketing and Market Research, Agricultural University, Wageningen, \\ The Netherlands
}

Accepted: 12 March 1973

\section{Summary}

In this article grading and sorting have been analysed as potential methods of market segmentation. Cross-price elasticity, viz cross-price flexibility coefficient, has been proposed as a criterion for effective market segmentation. Conditions for profit maximizing supplies in different grades have been derived under various market conditions.

The developed approach to testing of grading and sorting as a method of market segmentation has been applied to sorting of Dutch cucumbers and tomatoes. Effective market segmentation was not achieved by sorting. Sorting brought about quality segmentation to a limited extent only.

\section{Introduction}

Grading and sorting schemes, which regroup a heterogeneous supply of a product into homogeneous subgroups on the basis of specified criteria, are in use for a great many agricultural commodities. Arguments in favour of such schemes are: (a) the market becomes clearer, which facilitates purchasing for buyers and stimulates farmers to improve product quality; (b) the efficiency of trade is increased through standardization of supply. In general it may be expected that agricultural industry will introduce a grading or sorting scheme if this will increase its profits.

Which of the many grading schemes is optimum has been analysed by Zussman (1967) and others. However, the optimum grading scheme seems hard to assess in practice as yet. It may even be questioned whether grading and sorting today provide satisfactory market orientation; in fact it seems that for market segmentation more refined marketing policies are needed for agricultural products. Therefore, this paper concerns the testing of grading and sorting schemes as a means of market segmentation.

The following outline is suggested. In Section 2 the concepts market segmentation, grading and sorting will be discussed. Criteria to test whether a grading or sorting scheme brings about market segmentation will be proposed in Section 3. Some such criteria proposed will be applied to the market for cucumbers and tomatoes in the Netherlands in Section 4.

\section{The concepts market segmentation, grading and sorting}

Our definition of market segmentation follows the views of Smith (1956).

Let us assume that the set of all, say $M$, potential buyers of product $\mathrm{x}$ can be partitioned into disjunct subsets $\mathrm{M}_{1}, \mathrm{M}_{2} \ldots \mathrm{M}_{\mathrm{k}}$, being homogeneous within and different 
from each other with respect to buyers' wants and needs concerning product x. Market segmentation is the production of different types $x_{i}(i=1 \ldots k)$ of product $x$ such that $x_{i}$ suits, in particular, the specific wants and needs of the buyers in subset $M_{i}$.

Two comments are in order with respect to this definition. Firstly, it must be admitted, that some buyers of a product may have preference for different types of $x$, say $x_{i}$ and $x_{j}$, according to the purpose of use. In that case buyers belong to more subsets $\mathbf{M}_{1} \ldots \mathbf{M}_{\mathrm{k}}$. Also it should be stressed that homogeneity of wants and needs of consumers in a subset does not mean that wants and needs are exactly the same, but that wants and needs of consumers of, say, subset $\mathrm{M}_{\mathrm{i}}$ are situated in a specific range or that they are the same with regard to some particular properties of product $\mathrm{x}$. So market segmentation essentially means consumer orientation.

Grading and sorting divide a heterogeneous set of products $\mathrm{x}$ into homogeneous subsets $\mathrm{x}_{1} \ldots \mathrm{x}_{\mathrm{m}}$ on the basis of boundary values $\mathrm{z}=\left\{\mathrm{a}_{0_{\mathrm{i}}}<\mathrm{a}<\mathrm{a}_{\mathbf{1}_{\mathrm{i}}} \ldots \mathrm{p}_{\mathrm{0}_{\mathrm{i}}}<\mathrm{p}<\mathrm{p}_{\mathbf{1}_{\mathrm{i}}}\right\}$ of the product properties a . . p of $x, i=1 \ldots \mathrm{m}$.

The product properties used to classify products in classes $1 \ldots \mathrm{m}$ are chosen on the basis of their relevance to traders and consumers; properties which are used in grading are colour, sweetness, tenderness, and size and shape in case of sorting. The lower bounds, $a_{0} \ldots p_{0}$, and the upper bounds $a_{1} \ldots p_{1}$ determine the extent to which a particular grading system suits the needs and wants of buyers.

Grading and sorting and market segmentation both aim at the development of product categories which appeal to specific groups of buyers. It might be argued therefore that grading and sorting are potential methods of market segmentation. However, while market segmentation will be realized by a precise specification of marketing and production in advance, grading and sorting are done at the end of the production process. Hence differences between grades and sorting classes often are only differences in intensity of the same product properties, while market segmentation aims at producing products with essential differences, which suit particular segments of the market.

It should be stressed that a major purpose of grading and sorting is improvement of efficiency in trade, which is not a primary objective of market segmentation. However, improvent of efficiency by grading and/or sorting will here not be considered.

\section{Criteria to test the performance of grading and sorting as a method of market segmentation}

\subsection{A test criterion for effective market segmentation by grading and sorting: cross} elasticity with respect to price

Market segmentation attempts to serve the consumer by developing separate markets for specific types of a product. One might argue that market segmentation therefore is effective if consumers do not switch from one product type to another. Consequently, one might borrow methods to investigate the effectiveness of market segmentation from brand loyalty research. However often market data per grade or per sorting class are not available to such an extent that brand loyalty research procedures can be applied fruitfully. One will have to look for other test criteria.

It seems reasonable to expect that a buyer of products in grading class $\mathrm{i}$ will react less to a price change of products in a potentially competitive class when her preference for, and therefore loyalty towards, grading class $i$ is greater. A useful measure of the stability of demand for particular grades and sorting classes, and consequently 
a measure for the effectiveness of market segmentation by grading and sorting, seems the cross elasticity of demand for, say, product type $i$ in class $i$ with respect to the price of product type $\mathrm{j}$ in class $\mathrm{j}$. Hence, cross elasticity of demand with respect to price is proposed as a test criterion for the effectiveness of market segmentation by grading and/or sorting. A grading system of grades $1 \ldots \mathrm{m}$ leads to effective market segmentation if $\varepsilon_{\mathrm{ij}}=\left(\delta \mathrm{q}_{\mathrm{i}} / \delta \mathrm{p}_{\mathrm{j}}\right)\left(\mathrm{p}_{\mathrm{j}} / \mathrm{q}_{\mathrm{i}}\right)=0$, for $\mathrm{q}_{\mathrm{i}}=$ demand; $\mathrm{p}_{\mathrm{i}}=$ price; $\mathrm{i}, \mathrm{j}=1 \ldots$ $\mathrm{m} ; \mathbf{i} \neq \mathbf{j}$ and to ineffective market segmentation if $\varepsilon_{\mathrm{ij}}=\infty$.

The nearer the value of $\varepsilon_{\mathrm{ij}}$ is to zero, the greater is the effectiveness of grading as a market segmenting device. So almost effective market segmentation, $0<\varepsilon_{\mathrm{ij}}<1$, may be still economically attractive to producers.

Since often in agricultural markets the quantity supplied is the independent variable and price the dependent one, effectiveness of market segmentation might have to be measured in terms of $\varepsilon_{\mathrm{ij}}=\left(\delta \mathrm{p}_{\mathrm{i}} / \delta \mathrm{q}_{\mathrm{i}}\right)\left(\mathrm{q}_{\mathrm{j}} / \mathrm{p}_{\mathrm{i}}\right)$, for $\mathrm{p}_{\mathrm{i}}=$ price; $\mathrm{q}_{\mathrm{j}}=$ quantity; $\mathrm{i}, \mathrm{j}=1 \ldots \mathrm{m}$, $\mathrm{i} \neq \mathrm{j}$, the cross flexibility coefficients of price with respect to quantity.

Effective market segmentation means that an increase of market supply of grade $j$, and the consequent decrease in price of grade $j$, do not affect the demand for grade $i$, nor the price of grade $\mathrm{i}$ and therefore $\left(\delta \mathrm{p}_{\mathrm{i}} / \delta \mathrm{q}_{\mathrm{j}}\right)\left(\mathrm{q}_{\mathrm{j}} / \mathrm{p}_{\mathrm{i}}\right)=0$. Ineffective market segmentation implies that with an increase of $q_{j}$, and the consequent decrease in $F_{j}$, demand for grade $\mathrm{i}$ switches over to grade $\mathrm{j}$, and consequently $\left(\delta \mathrm{p}_{\mathrm{i}} / \delta \mathrm{q}_{\mathrm{j}}\right)\left(\mathrm{q}_{\mathrm{i}} / \mathrm{p}_{\mathrm{i}}\right) \rightarrow-\infty$.

\subsection{Optimum supply for effective or almost effective market segmentation}

Given a particular grading scheme, profit maximizing supply in different grades can be derived as follows:

$$
\begin{aligned}
\mathrm{W} & =\Sigma_{\mathrm{i}=1}^{\mathrm{k}} \mathrm{x}_{\mathrm{i}} \mathrm{w}_{\mathrm{i}}=\max . \\
\mathrm{w}_{\mathrm{i}} & =\mathrm{p}_{\mathrm{i}}-\mathrm{c}_{\mathrm{i}} \\
\mathrm{p}_{\mathrm{i}} & =\mathrm{f}_{\mathrm{i}}=\left(\mathrm{x}_{1} \ldots \mathrm{x}_{\mathrm{k}}\right)
\end{aligned}
$$

where

$$
\begin{aligned}
& \mathrm{x}_{\mathrm{i}}=\text { supply in grade } \mathrm{i}(\mathrm{i}=1 \ldots \mathrm{k}) \\
& \mathrm{p}_{\mathrm{i}}=\text { price/ unit in grade } \mathrm{i}(\mathrm{i}=1 \ldots \mathrm{k}) \\
& \mathrm{c}_{\mathrm{i}}=\text { costs/unit in grade } \mathrm{i}(\mathrm{i}=1 \ldots \mathrm{k}) \\
& \mathrm{w}_{\mathrm{i}}=\text { profit/unit in grade } \mathrm{i}(\mathrm{i}=1 \ldots \mathrm{k})
\end{aligned}
$$

Under the assumption that $x_{i}$ and $x_{j}(i \neq j)$ are independent and also $x_{i}$ and $c_{j}(i \neq j)$ are independent, profit maximization will be arrived at if:

$$
\left[\begin{array}{ccc}
\frac{\partial w_{1}}{\partial x_{1}} & \cdots & \frac{\partial w_{k}}{\partial x_{1}} \\
\vdots & \vdots \\
\frac{\partial w_{1}}{\partial x_{k}} & \cdots & \frac{\partial w_{k}}{\partial x_{k}}
\end{array}\right] \cdot\left[\begin{array}{c}
x_{1} \\
\vdots \\
x_{k}
\end{array}\right]=\left[\begin{array}{c}
-w_{1} \\
\vdots \\
-w_{k}
\end{array}\right]
$$


and second-order conditions are fulfilled.

Under the assumption of effective market segmentation, i.e. $\delta \mathrm{w}_{\mathrm{i}} / \delta \mathrm{x}_{\mathrm{j}}=0$ for $\mathrm{i} \neq \mathrm{j}$, the conditions arrived at in Eq. 3.4 become $\left(\delta \mathrm{w}_{\mathrm{i}} / \delta \mathrm{x}_{\mathrm{i}}\right) \mathrm{x}_{\mathrm{i}}=-\mathrm{w}_{\mathrm{i}}, \mathrm{i}=1 \ldots \mathrm{k}$ which, for $\mathrm{c}_{\mathrm{i}}=\mathrm{c}_{\mathrm{j}}=\mathrm{c}$ and $\mathrm{c}_{\mathrm{i}}$ is independent of $\mathrm{x}_{\mathrm{i}}$, become:

$$
\mathrm{p}_{\mathrm{i}} / \mathrm{p}_{\mathrm{i}}=\left(1+1 / \varepsilon_{\mathrm{i}}\right) /\left(1+1 / \varepsilon_{\mathrm{i}}\right), \text { for } \varepsilon_{\mathrm{i}}=\left(\delta \mathrm{x}_{\mathrm{i}} / \delta \mathrm{p}_{\mathrm{i}}\right)\left(\mathrm{p}_{\mathrm{i}} / \mathrm{x}_{1}\right)
$$

If, in addition, it is required that $\mathrm{p}_{1}>\mathrm{p}_{2}>\mathrm{p}_{3} \ldots>\mathrm{p}_{\mathrm{k}}$ because of the quality image of grade 1 against the quality image of grade 2 etc., profit maximizing conditions are

$$
\left(\delta \mathrm{p}_{\mathrm{i}} / \delta \mathrm{x}_{\mathrm{i}}\right) \mathrm{x}_{\mathrm{i}}-\left(\delta \mathrm{p}_{\mathrm{j}} / \delta \mathrm{x}_{\mathrm{j}}\right) \mathrm{x}_{\mathrm{j}}=\left(\mathrm{p}_{\mathrm{j}}-\mathrm{p}_{\mathrm{i}}\right)<0
$$

for $\mathrm{i}<\mathrm{j} ; \mathrm{i}, \mathrm{j}=1 \ldots \mathrm{k}$.

This additional condition $\mathrm{p}_{\mathrm{i}}>\mathrm{p}_{\mathrm{j}}$ implies that $\left(1 / \varepsilon_{\mathrm{j}}+1\right) /\left(1 / \varepsilon_{\mathrm{i}}+1\right)>1$ or $\left|\varepsilon_{\mathrm{i}}\right|$ $<\left|\varepsilon_{\mathrm{j}}\right|$ for $\varepsilon_{\mathrm{i}}<-1, \varepsilon_{\mathrm{j}}<-1$ and $\left|\varepsilon_{\mathrm{i}}\right|>\left|\varepsilon_{\mathrm{j}}\right|$ for $0>\varepsilon_{\mathrm{i}}>-1$ and $0>\varepsilon_{\mathrm{j}}>-1$.

Under only slightly weaker effectiveness of market segmentation, conditions with respect to profit maximizing supply become much more complicated. For instance, suppose that adjacent grades only are competitive, i.e. $\delta \mathrm{p}_{\mathrm{i}} / \delta \mathrm{x}_{\mathrm{i}+\mathrm{j}+1}=0$, for $\mathrm{i}, \mathrm{j}=1$ $\ldots k$ and $(\mathrm{i}+\mathrm{j}) \leqslant(\mathrm{k}-1) ; \delta \mathrm{p}_{\mathrm{i}} / \delta \mathrm{x}_{\mathrm{i}-1-\mathrm{j}}=0$, for $\mathrm{i}, \mathrm{j}=1 \ldots \mathrm{k}$ and $(\mathrm{i}-\mathrm{j}) \geqslant 2$.

Under this assumption plus the assumption $c_{i}=c_{j}=c_{0}$ the conditions for profit maximizing supply are:

$$
\Sigma_{\mathrm{t}=0}^{2}\left(\delta \mathrm{p}_{\mathrm{i}+\mathrm{t}-1} / \delta \mathrm{x}_{\mathrm{i}}\right) \mathrm{x}_{\mathrm{i}+\mathrm{t}-1}+\mathrm{p}_{\mathrm{i}}=\Sigma_{\mathrm{t}=0}^{2}\left(\delta \mathrm{p}_{\mathrm{i}+\mathrm{t}} / \delta \mathrm{x}_{\mathrm{i}+1}\right) \mathrm{x}_{\mathrm{i}+\mathrm{t}}+\mathrm{p}_{\mathrm{i}+1}
$$

or

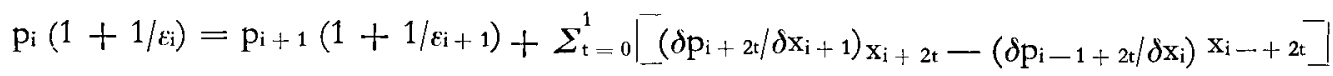

for $\varepsilon_{\mathrm{i}}$ being the price elasticity of demand for grade $i$.

\subsection{Feasibility of profit maximizing supply for a given grading scheme}

3.3.1 Variability of supply in different grades. Because of varying weather conditions or other random effects variability of production in different grades may be substantial. Then only a monopolist will be able to adapt market supply in different grades to optimum supply by destroying some produce. However even in a monopolistic market situation, a great variation in production of different grades will diminish the opportunity of realizing optimum supply in the market. For that reason variance of production in different grades is suggested as a test criterion for feasibility of optimum supply.

3.3.2 Correlation between supply in different grades. If production in different grades is strongly correlated, it will be difficult to vary independently supply in different grades. Therefore it might be argued that optimum supply conditions so derived, have no practical value except for a situation in which a monopolistic marketing agency can control market supply by destruction or storage.

When there is a constant ratio between supplies in different grading classes it still seems possible to determine profit maximizing supply. Since then for Eq. 3.1, 3.2 and 3.3 it holds: $\mathrm{x}_{\mathrm{i}}=\gamma_{\mathrm{i}} \mathrm{x},(\mathrm{i}=1 \ldots \mathrm{k})$, for $\Sigma_{\mathrm{i}=1}^{\mathrm{k}} \gamma_{\mathrm{i}}=1$ and $\mathrm{x}=$ total supply, Eq. 3.1, 3.2 and 3.3 become: 


$$
\mathrm{W}=\Sigma_{\mathrm{i}=1}^{\mathrm{k}} \mathrm{x}_{\mathrm{i}}\left(\mathrm{p}_{\mathrm{i}}-\mathrm{c}_{\mathrm{i}}\right)=\sum_{\mathrm{i}=1}^{\mathrm{k}} \gamma_{\mathrm{i}} \mathrm{x}\left(\mathrm{p}_{\mathrm{i}}-\mathrm{c}_{\mathrm{i}}\right)=\sum_{\mathrm{i}=1}^{\mathrm{k}} \gamma_{\mathrm{i}} \mathrm{x}\left[\mathrm{f}_{\mathrm{i}}\left(\gamma_{1} \mathrm{x} \ldots \gamma_{\mathrm{k}} \mathrm{x}\right)-\mathrm{c}_{\mathrm{i}}\right] .
$$

Profit maximizing conditions Eq. 3.4 can be simplified to:

$$
\mathrm{dw} / \mathrm{dx}=0 \text {, or } \Sigma_{\mathrm{i}=1}^{\mathrm{k}} \gamma_{\mathrm{i}}\left[\mathrm{f}_{\mathrm{i}}\left(\gamma_{1} \mathrm{x} \ldots \gamma_{\mathrm{k}} \mathrm{x}\right)-\mathrm{c}_{\mathrm{i}}\right]+\mathrm{x} \Sigma_{\mathrm{i}=1}^{\mathrm{k}} \gamma_{\mathrm{i}}\left[\mathrm{df}_{\mathrm{i}}\left(\gamma_{1} \mathrm{x} \ldots \gamma_{\mathrm{k}} \mathrm{x}\right)\right] / \mathrm{dx}=0
$$

If $f_{i}(x)$ is a linear function in $x$, a unique optimizing value for $x$ can be determined when $\mathrm{f}_{\mathrm{i}}\left(\mathrm{)}, \gamma_{\mathrm{i}}\right.$ and $\mathrm{c}_{\mathrm{i}}$, for $\mathrm{i}=1 \ldots \mathrm{k}$, are known.

\subsection{Quality segmentation}

In spite of large cross elasticities, i.e. absence of effective market segmentation, there might be systematic differences between prices of different grades. These differences must be the consequence of quality differences between grades as experienced by consumers. Grading then differentiates supply so that differences between grades are considered to be attractive, but not essential by the consumer. We suggest for this case the name quality segmentation.

\section{An application: sorting of cucumbers and tomatoes in the Netherlands}

Sorting of cucumbers and tomatoes in the Netherlands has been investigated on the basis of criteria proposed in Section 3. Cucumbers are sorted by size in classes: $\geqslant 76 \mathrm{~cm} /$ unit; $51-<76 \mathrm{~cm}, 36-<51 \mathrm{~cm} ; 26-<36 \mathrm{~cm}$. Tomatoes are sorted on the basis of size in Class A $(47-<57 \mathrm{~mm})$, Class B $(57-<67 \mathrm{~mm})$, Class C (40 $<47 \mathrm{~mm})$ and Class CC $(<40 \mathrm{~mm})$. Dutch cucumbers and tomatoes are sold in a number of separated geographical markets: domestic market, and export markets, like West Germany, England, France and Sweden, whose interest in the respective sorting classes differs. For that reason it seems worthwhile to find out whether market segmentation has been brought about by sorting.

\subsection{Relationship between supply in different sorting classes}

It appears that supplies of tomatoes in different sorting classes over the period 1968 up to and including 1970 are strongly correlated, especially for adjacent sorting classes. For tomatoes this correlation holds especially for sorting classes A, B and C. For cucumbers the correlation between supplies in different sorting classes is weaker (Table 1).

Both for cucumbers and for tomatoes, the correlation between prices of different sorting classes is higher than the correlation between quantities supplied (Table 1).

\subsection{Cross-price flexibility coefficients between sorting classes}

To test whether sorting brings about market segmentation, the following functions will be estimated for tomatoes with monthly market data over the period 1968 up to and including 1970.

$$
\begin{aligned}
& \mathrm{p}_{\mathrm{ij}}=\mathrm{f}_{\mathrm{i}}\left(\mathrm{q}_{A_{j}}, \mathrm{q}_{\mathrm{Bj}}, q_{C_{j}}, q_{\mathrm{CC}_{j}}, \mathrm{ex}_{\mathrm{j}}, \mathrm{D}_{1}, \mathrm{D}_{2}\right)+\mathrm{u}_{\mathrm{ij}} \\
& \mathrm{ex}_{\mathrm{j}}=\mathrm{g}\left(\mathrm{q}_{\mathrm{j}}, \mathrm{D}_{1}, \mathrm{D}_{2}\right)+\mathrm{v}_{\mathrm{j}}
\end{aligned}
$$


Table 1. Estimates of correlation coefficients between supply in different sorting classes for Dutch cucumbers and tomatoes (lower figures of each pair) and prices of different sorting classes for Dutch cucumbers and tomatoes (upper figures). Estimates are made with monthly data of supply and prices at Dutch auctions over 1968, 1969 and 1970.

\begin{tabular}{lrrr}
\hline $\begin{array}{l}\text { Cucumbers } \\
\text { Sorting class }\end{array}$ & $51-76$ & $36-51$ & $26-36$ \\
76 & 0.962 & 0.898 & 0.788 \\
& 0.828 & 0.113 & -0.339 \\
$51-76$ & & 0.972 & 0.762 \\
& & 0.574 & -0.045 \\
$36-51$ & & & 0.747 \\
& & & 0.669 \\
\hline Tomatoes & & & \\
Sorting class & $\mathrm{B}$ & $\mathrm{C}$ & $\mathrm{CC}$ \\
& & & \\
A & 0.986 & 0.998 & 0.977 \\
& 0.823 & 0.855 & 0.567 \\
B & & 0.985 & 0.967 \\
& & 0.542 & 0.236 \\
C & & & 0.983 \\
& & & 0.866 \\
\hline
\end{tabular}

Source of unpublished data: the Centraal Bureau van de Tuinbouwveilingen, Den Haag.

where $\mathrm{p}_{\mathrm{ij}}=$ monthly tomato price of sorting class $\mathrm{i}$ in guilders per $\mathrm{kg}$ at Dutch auctions for $\mathrm{i}=\mathrm{A}, \mathrm{B}, \mathrm{C}$ and $\mathrm{CC}$;

$\mathrm{q}_{\mathrm{Ai}}, \mathrm{q}_{\mathrm{B},}, \mathrm{q}_{C_{j}}$, and $\mathrm{q}_{C_{\mathrm{j}}}=$ monthly tomato sales in sortingclasses $\mathrm{A}, \mathrm{B}, \mathrm{C}$ and $\mathrm{CC}$ in 1000 tonnes at Dutch auctions;

$\mathrm{ex}_{\mathrm{j}}=$ monthly Dutch tomato exports in 1000 tonnes;

$D_{1}, D_{2}=$ dummy variables $D_{1}=1$ in 1969 and 0 in 1968 and $1970 ; D_{2}=1$ in 1970 and 0 in 1968 and 1969;

$\mathrm{q}_{\mathfrak{j}}=$ total monthly supply of tomatoes at Dutch auctions in 1000 tonnes;

$\mathrm{u}_{\mathrm{i}}=$ random error; $\mathrm{u}_{\mathrm{ij}} \sim \mathrm{N}\left(\mathrm{o}, \sigma_{\mathrm{i}}^{2}\right)$;

$v_{j}=$ random error; $v_{j} \sim N\left(o, \sigma^{2}\right)$

The model suggests that price in a specific sorting class is a function of supply in all sorting classes and of total exports. Dummy variables are introduced to take care of shifts in the market. Preferably exports of separate sorting classes should have been introduced, but data were not available.

An analogous model has been set up for cucumbers:

$$
\begin{aligned}
& \mathrm{p}_{\mathrm{ij}}=\mathrm{f}_{\mathrm{i}}\left[\mathrm{q}(\geqslant 76)_{\mathrm{i}}, \mathrm{q}(51-<76)_{j}, \mathrm{q}(36-<51)_{\mathrm{i}}, \mathrm{q}(26-<36)_{j}, \mathrm{ex}_{\mathrm{j}}, \mathrm{D}_{1}, \mathrm{D}_{2}\right]+\mathrm{u}_{\mathrm{ij}} \\
& \mathrm{ex}_{\mathrm{j}}=\mathrm{g}\left(\mathrm{q}_{\mathrm{j}}, \mathrm{D}_{1}, \mathrm{D}_{2}\right)+\mathrm{v}_{\mathrm{j}}
\end{aligned}
$$




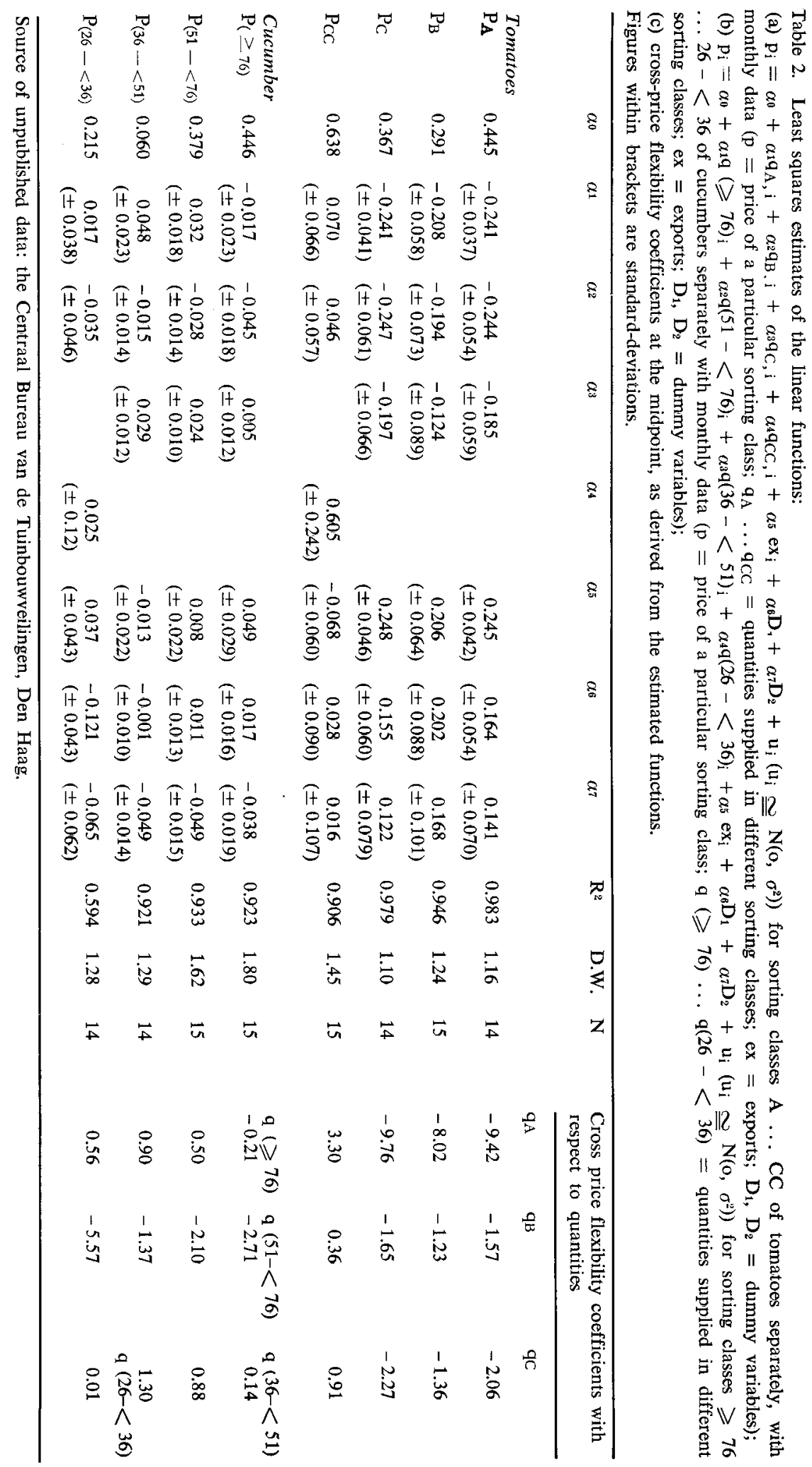


where $\mathrm{p}_{\mathrm{ij}}=$ monthly price of cucumbers of sorting class $\mathrm{i}$ in guilders per unit at Dutch auctions, for $\mathrm{i}=\geqslant 76,51-<76,36-<51$ and $26-<36$;

$\mathrm{q}(\geqslant 76)$, $\mathrm{q}(51-<76)$, q $(36-<51)$ and $\mathrm{q}(26-<36)=$ monthly sales of cucumbers in the respective sorting classes at Dutch auctions in 1000000 units;

$\mathrm{ex}_{\mathbf{j}}=$ monthly Dutch cucumber exports in 1000000 units;

$D_{1}, D_{2}=$ dummy variables: $D_{1}=1$ in 1969 and 0 in 1968 and $1970 ; D_{2}=1$ in 1970 and 0 in 1968 and 1969;

$\mathrm{q}=$ total supply of cucumbers at Dutch auctions in 1000000 units;

$\mathrm{u}_{\mathrm{ij}}=$ random error; $\mathrm{u}_{\mathrm{ij}} \sim \mathrm{N}\left(\mathrm{o}, \sigma_{\mathrm{i}}{ }^{2}\right)$;

$\mathrm{v}_{\mathrm{j}}=$ random error; $\mathrm{v}_{\mathrm{i}} \sim \mathrm{N}\left(\mathrm{o}, \sigma^{2}\right)$.

Functions $\mathrm{f}_{\mathrm{i}}(\mathrm{)}$, and $\mathrm{g}(\mathrm{)}$ ) are assumed to be linear. Since the model is recursive, estimation by Least Squares is appropriate. Functions have been estimated for every sorting class i separately. Least Squares estimates of Eq. 4.1 and 4.3 have been reported in Table 2 . It appears that cross-price flexibility coefficients for tomatoes at the midpoint, especially with respect to quantity sold in sorting class $A$, are high and statistically significant, notwithstanding the intercorrelation between supply in different sorting classes. For cucumbers cross-price flexibility of prices with respect to quantity sold in sorting class $51-<76$ are large and statistically significant. Probably these large cross-price flexibility coefficients are partly caused by the large share of sorting class $\mathrm{A}$ and sorting class $51-<76$ in total sales: share of sorting class $\mathrm{A}$ in tomato sales at Dutch auctions amounted to $68 \%$ in 1970 and share of sorting class $51-<76$ in cucumber sales amounted to $53 \%$ in the same year. So, it must be concluded that no effective market segmentation has been realized by the sorting schemes in use for tomatoes and cucumbers.

In view of the large share of exports in total supply it seems reasonable that most variation in export can be explained by production. Eq. 4.2 will not be discussed further, since it is of no interest in the context of this paper.

\subsection{Price differences between sorting classes: testing for quality segmentation}

4.3.1 It has been pointed out in Section 3.4 that even without effective market segmentation average prices in different sorting classes might differ significantly. This point has been analysed for tomatoes and cucumbers with the following model:

$$
\mathrm{p}_{\mathrm{i}}=\mathrm{f}\left(\mathrm{q}_{\mathrm{i}}, \mathrm{ex}_{\mathbf{i}}, \mathrm{D}_{\mathbf{1}}{ }^{\prime}, \mathrm{D}_{\mathbf{2}}{ }^{\prime}, \mathrm{D}_{\mathbf{3}}{ }^{\prime}, \mathrm{D}_{1}, \mathrm{D}_{\mathbf{2}}\right)+\mathrm{u}_{\mathrm{ij}}
$$

$\mathrm{p}_{\mathrm{i}}=$ monthly price of tomatoes (cucumbers) in different sorting classes at Dutch auctions in guilders per $\mathrm{kg}$ (per unit for cucumber);

$\mathrm{q}_{\mathrm{i}}=$ monthly supply of tomatoes (cucumbers) at Dutch auctions in 1000 tonnes (1 000000 units for cucumbers);

$\mathrm{ex}_{\mathrm{i}}=$ monthly exports of Dutch tomatoes (cucumbers) in 1000 tonnes (1.000 000 units for cucumbers);

$D_{1}, D_{2}=$ dummy variables: $D_{1}=1$ in 1969 and 0 in other years; $D_{2}=1$ in 1970 and 0 in other years;

$\mathrm{D}_{1}{ }^{\prime}, \mathrm{D}_{2}{ }^{\prime}, \mathrm{D}_{3}{ }^{\prime}=$ dummy variables;

$D_{1}^{\prime}=1$ for prices of sorting class $A$ (for cucumbers of sorting class $\geqslant 76$ ), otherwise $\mathrm{D}^{\prime}{ }^{\prime}=0$

$\mathrm{D}_{2}^{\prime}=1$ for prices of sorting class $\mathrm{B}$ (for cucumbers of sorting class $51-<76$ ), otherwise $\mathrm{D}_{2}^{\prime}=0$; 


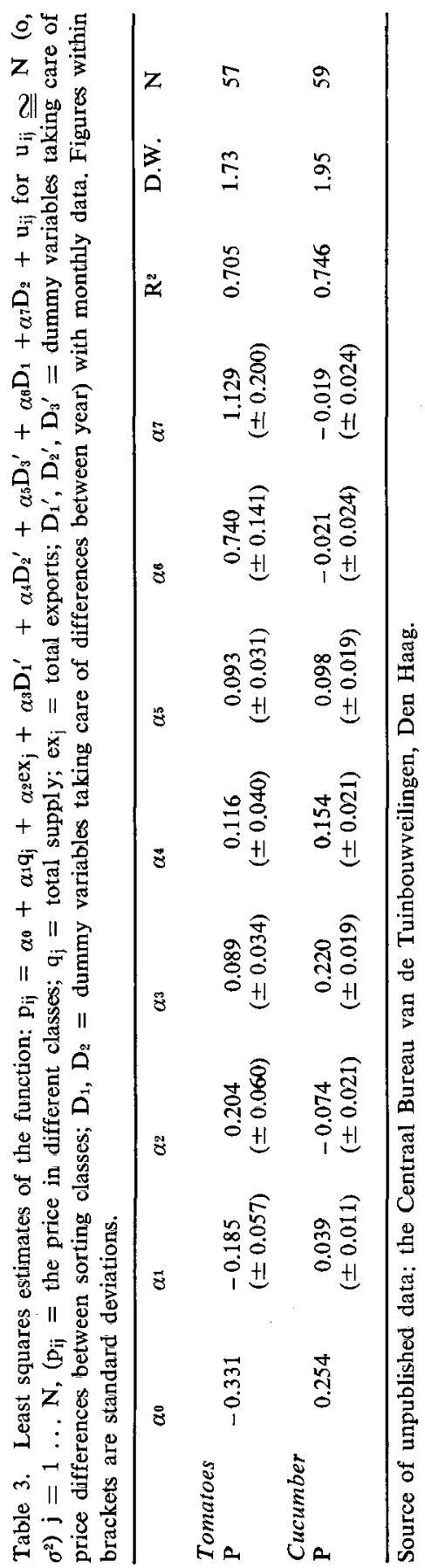


$\mathbf{D}_{\mathbf{3}}{ }^{\prime}=1$ for prices of sorting class $\mathrm{C}$ (for cucumbers of sorting class $36-<51$ ), otherwise $D_{3}{ }^{\prime}=0$;

$\mathrm{u}_{\mathrm{ij}}=$ random error: $\mathrm{u}_{\mathrm{ij}} \sim \mathrm{N}\left(\mathrm{o}, \sigma^{2}\right)$.

$f()$ is assumed to be linear.

Function 4.5 has been estimated by Least Squares with monthly data over the period 1968 - 1970 (Table 3). The estimates of the coefficients of $\mathrm{D}_{1}{ }^{\prime}, \mathrm{D}_{2}{ }^{\prime}$ and $\mathrm{D}_{3}{ }^{\prime}$ were statistically significant both for cucumbers and tomatoes. It implies that there is a statistically significant price difference between prices in Classes A, B, C versus class CC. It looks as if average prices in Class $A$ are slightly higher than those in Classes $B$ and $\mathrm{C}$, but this difference cannot be shown to be statistically significant.

The statistically significant difference between prices of cucumbers per unit seems self evident because of the measurement of prices and quantities per units, which are of different size.

4.3.2 Whether differences between sorting classes $\mathrm{A}$ and $\mathrm{CC}$ for tomatoes, and between $\geqslant 76$ and $26-<36$ for cucumbers change throughout the market season has been analysed by estimating the model:

$$
\left(\mathrm{p}_{\mathrm{i}}-\mathrm{p}_{\mathrm{i}}\right)_{\mathrm{k}}=\mathrm{f}\left(\mathrm{t}, \mathrm{D}_{1}, \mathrm{D}_{2}\right)+\mathrm{u}_{\mathrm{k}}
$$

$\left(\mathrm{p}_{\mathrm{i}}-\mathrm{p}_{\mathrm{j}}\right)_{\mathbf{k}}=$ difference between weekly prices of tomatoes (cucumbers) of sorting

class $\mathrm{A}$ and sorting class $\mathrm{CC}$ (cucumbers: $\geqslant 76$ and $26-<36$ ) at Dutch auctions in guilders/kg (guilders per cucumber);

$\mathrm{t}=$ time indicating month within a season;

$D_{1}, D_{2}=$ dummy variables: $D_{1}=1$ in 1969 and 0 otherwise; $D_{2}=1$ in 1970 and 0 otherwise;

$\mathrm{u}_{\mathrm{k}}=$ random error: $\mathrm{u}_{\mathrm{k}} \sim \mathrm{N}\left(\mathrm{o}, \sigma^{2}\right)$;

$\mathrm{f}(\mathrm{l})$ is assumed to be linear.

Estimation of function 4.6 by Least Squares shows that within progress of season the difference between average prices per $\mathrm{kg}$ of tomatoes in class $\mathrm{A}$ and class $\mathrm{CC}$ becomes less. (Table 4). This does not hold for price differences between cucumbers in Classes $\geqslant 76$ and $26-<36$.

Table 4. Least squares estimates of the functions: $\left(p_{i}-p_{k}\right)_{j}=\alpha_{0}+\alpha_{1} t+\alpha_{2} D_{1}+\alpha_{3} D_{2}+u_{j}$ for $u_{j}$ $\sim N\left(o, \sigma^{2}\right) ; j=1 \ldots N ;\left(p_{i}-p_{k}\right)_{j}=$ price difference $(1=A$ and $K=C C$ in the case of tomatoes, $\mathrm{i}=\geqslant 76$ and $\mathrm{k}=26-<36$ in the case of cucumbers; $\mathrm{t}=$ trend within year; $\mathrm{D}_{1}, \mathrm{D}_{2}$ dummies taking care of price differences between different years) with monthly data. Figures within brackets are standard deviations.

\begin{tabular}{|c|c|c|c|c|c|c|c|}
\hline & $\alpha 0$ & $\alpha t$ & $\alpha^{2}$ & $\alpha_{3}$ & $\mathrm{R}^{2}$ & D.W. & $\mathbf{N}$ \\
\hline $\begin{array}{l}\text { Tomatoes } \\
\left(\mathrm{P}_{\mathrm{A}}-\mathrm{P}_{\mathrm{CC}}\right)\end{array}$ & 0.317 & $\begin{array}{l}-0.026 \\
( \pm 0.004)\end{array}$ & $\begin{array}{c}0.207 \\
( \pm 0.050)\end{array}$ & $\begin{array}{c}0.208 \\
( \pm 0.051)\end{array}$ & 0.607 & 1.92 & 44 \\
\hline $\begin{array}{l}\text { Cucumber } \\
\left(\mathrm{P} \geq 76-\mathrm{P}_{20-39)}\right.\end{array}$ & 0.287 & $\begin{array}{l}-0.00003 \\
( \pm 0.002)\end{array}$ & $\begin{array}{c}0.051 \\
( \pm 0.030)\end{array}$ & $\begin{array}{c}0.011 \\
( \pm 0.030)\end{array}$ & 0.088 & 1.90 & 45 \\
\hline
\end{tabular}

Source of unpublished data: the Centraal Bureau van de Tuinbouwveilingen, Den Haag.

Neth. J. agric. Sci. 21 (1973) 


\subsection{Conclusion}

It appears that neither for tomatoes nor for cucumbers sorting leads to effective market segmentation. For tomatoes a statistically significant price level between sorting classes $\mathrm{A}, \mathrm{B}, \mathrm{C}$ on the one side and sorting class $\mathrm{CC}$ on the other side, could be established. So sorting only causes a slight quality segmentation. It will be necessary to develop a more refined marketing policy, if market segmentation is considered to be a good idea for cucumbers or tomatoes.

\section{Acknowledgments}

The author is indebted to Dr S. Sosnick for stimulating comments and to Mr. J. Bijkerk for computational assistence.

\section{References}

Smith, W. R., 1956. Product differentiation and market segmentation as alternative marketing strategies. J. Marketing 21: 3-8.

Zussman, P., 1967. A theoretical basis for determination of grading and sorting schemes. J. Farm Econ. 49 (1): 89-106. 